ROBERTO CARDOSO

ESTUDO SOBRE A INCIDÊNCIA DAS POROSIDADES E SUA IDENTIFICAÇÃO EM UMA LIGA DE ALUMÍNIO A356 


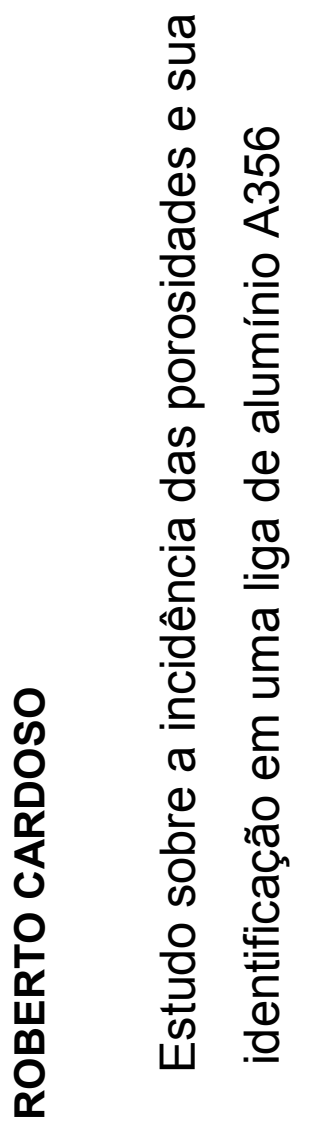

옹 
ROBERTO CARDOSO

ESTUDO SOBRE A INCIDÊNCIA DAS POROSIDADES E SUA IDENTIFICAÇÃO EM UMA LIGA DE ALUMÍNIO A356

Dissertação apresentada à Escola Politécnica da Universidade de São Paulo para a obtenção do título de Mestre em Engenharia

São Paulo 
ROBERTO CARDOSO

\title{
ESTUDO SOBRE A INCIDÊNCIA DAS POROSIDADES E SUA IDENTIFICAÇÃO EM UMA LIGA DE ALUMÍNIO A356
}

\author{
Dissertação apresentada à Escola \\ Politécnica da Universidade de São \\ Paulo para a obtenção do título de \\ Mestre em Engenharia
}

\author{
Área de Concentração: \\ Engenharia Metalúrgica e de \\ Materiais
}

Orientador: Prof. Doutor

André Paulo Tschiptschin

São Paulo 


\section{FICHA CATALOGRÁFICA}

\section{Cardoso, Roberto}

Estudo sobre a incidência das porosidades e sua identificacão em uma liga de alumínio A356 / R. Cardoso. -- São Paulo, 2007.

$145 \mathrm{p}$.

Dissertação (Mestrado) - Escola Politécnica da Universidade de São Paulo. Departamento de Engenharia Metalúrgica e de Materiais.

1.Liga de alumínio A356 2.Porosidade (Identificação) I.Universidade de São Paulo. Escola Politécnica. Departamento de Engenharia Metalúrgica e de Materiais II.t. 


\section{DEDICATÓRIA}

Dedico este trabalho aos meus alunos 


\section{AGRADECIMENTOS}

Ao professor Dr. André Paulo Tschiptschin pela orientação, pelo constante estímulo e confiança transmitida.

Aos professores Dr.Hélio Goldenstein, Dr. Ricardo Fuoco pela sua orientação, amparo no desenvolvimento da pesquisa e pela demonstração de amizade, Dr. J.D.T. Capocchi, à Diretoria e aos amigos da Fundição Alvorada, ao Engenheiro Paulo Marchina, Diretor Técnico da Magal Indústria e Comércio Ltda., Me. Maria da Graça Marcatto, Chefe do Departamento de Mecânica da Faculdade de Tecnologia de São Paulo, ao I.P.T. Instituto de Pesquisas Tecnológicas, à Foseco Indústria e Comércio Ltda., a Alfa Trend Indústria e Comércio Ltda. e a todos que colaboraram direta ou indiretamente na execução deste trabalho. 


\section{RESUMO}

Este trabalho procurou identificar o defeito que ocorria no teste de estanqueidade de uma peça e apresentar a correlação entre o nível de porosidade encontrado no produto fundido com a liga de alumínio A356 e os processos de fusão e de manutenção sob temperaturas controladas, o teor de hidrogênio, o sistema de enchimento e de alimentação, obedecendo ao princípio de solidificação direcional e o posicionamento do modelo em relação à linha de divisão. Foram efetuadas algumas experiências com diferentes tempos de introdução de nitrogênio para a purificação do metal, com a inversão do modelo em relação ao plano de partição do molde, com a modificação das dimensões do sistema de enchimento, com a substituição dos massalotes laterais por outros com luvas exotérmicas e utilizando-se resfriadores. Tentou-se verificar os benefícios que os filtros cerâmicos proporcionam aos fundidos, principalmente quanto à diminuição do nível de porosidade, menor turbulência e maior capacidade de reter as inclusões e parte dos filmes de óxidos. Para comproválos, propôs-se a fundição de peças, em moldes confeccionados pelo processo de areia à verde, com diferentes tipos de filtros cerâmicos nos canais de distribuição. As amostras foram analisadas no Laboratório Metalográfico do Departamento de Engenharia Metalúrgica e de Materiais da Escola Politécnica da Universidade de São Paulo e no Laboratório de Metalurgia e de Materiais Cerâmicos do Instituto de Pesquisas Tecnológicas de São Paulo. Após a análise dos resultados em microscópio óptico, microscópio eletrônico de varredura e em espectrômetro por emissão de energia observou-se que o problema está relacionado principalmente com a alimentação e a solidificação direcional e não somente com o teor de hidrogênio.

Palavras-chave: Liga de alumínio A356. Nível de porosidade. Teor de hidrogênio. Filmes de óxidos. Sistema de enchimento. Alimentação. Resfriadores. Filtros cerâmicos. Microscópio óptico. Microscópio eletrônico de varredura. Espectrômetro por emissão de energia 


\begin{abstract}
The objective of this work is to study the type of defect identified during the pressure tightness test of aluminum parts and to establish a relationship between porosity level of an A356 aluminum alloy and the production processes, hydrogen level, feeding system, and directional solidification.

Different nitrogen blowing times, inversion of the mould pattern, relative to the partition line, changing of the feeding system dimensions, replacement of the lateral feeding by exothermic gloves and the use of chills where tested. Ceramic filters were also tested, in order to evaluate their influence on the formation of porosities and on the porosity level, through a decrease of turbulence and an increase in the capacity of retaining non-metallic inclusions and part of the oxide films.

Casting was performed by the green sand process using different ceramic filters. The obtained parts were metallographicaly analyzed through optical and scanning electronic microscopy using also EDS analysis. The results showed that porosity is related with the feeding conditions and directional solidification besides the hydrogen content of the alloys.
\end{abstract}

Key words: A356 Aluminum alloy, Porosity, Hydrogen, Oxide films, Feeding Systems, Chills, Ceramic filters 


\section{LISTA DE FIGURAS}

Figura 1 - Diagrama de equilíbrio para as ligas do sistema AI-Si (4). .17

Figura 2 - a) Esquema do trecho da curva de análise térmica da liga A356 sem a adição dos elementos químicos externos; no gráfico b) a curva derivada, mostrando o super - resfriamento no início da solidificação. TE= temperatura líquidus; $\mathrm{TN}=$ temperatura de nucleação; TMin máximo super- resfriamento; $\mathrm{TG}=$ temperatura de crescimento (equilíbrio); $\mathrm{t}$ Rec= tempo de recalescência. (4).

Figura 3 - a) Esquema do trecho da curva de análise térmica do alumínio puro e na figura b) a curva derivada. $\mathrm{A}$ liga foi refinada com $\mathrm{Al}-5 \% \mathrm{Ti}-1 \% \mathrm{~B}$. $\mathrm{TN}=$ temperatura de nucleação; $\mathrm{TE}=$ temperatura líquidus do diagrama $\mathrm{Al}$ $\mathrm{Ti} ; \mathrm{TE}=$ temperatura líquidus da liga $\mathrm{Al}-\mathrm{Si} ; \mathrm{TG}=$ temperatura de crescimento (equilíbrio). (4).

Figura 4 - Esquema ilustrando a segregação do soluto para o líquido na frente da interface durante a solidificação de uma liga metálica. C0 - concentração de soluto no líquido; CL - concentração de soluto na interface sólida / líquida; CS - concentração de soluto no sólido. (4). 22

Figura 5 - Microestrutura da liga A356, onde se observa o aspecto modificado do Silício devido à adição de sódio. A micrografia superior foi obtida através do microscópio óptico com ampliação de $200 \times$ e a micrografia b), através do M.E.V., após ataque profundo com $\mathrm{NaOH} 20 \%$. 400x (4)... 24

Figura 6 - Gráfico representando a solubilidade do hidrogênio no alumínio a pressão de $1 \mathrm{~atm}$

Figura 7 - Micrografia de liga A356 sem modificação, contendo uma microporosidade

Figura 8 - Micrografia de liga A356 modificada com estrôncio, contendo uma microporosidade.

Figura 9 - Esquema da formação dos respingos, óxidos dobrados e do envolvimento do ar no preenchimento do molde (11) 30

Figura 10 - O esquema representa a entrada de ar durante o preenchimento da cavidade do molde, a formação da porosidade e o arraste dos óxidos 
Figura 11 - Comparação entre as amostras obtidas ao mesmo tempo, com a liga Al7Si0.4Mg, submetidas à solidificação sob pressão de : a) 1 atmosfera, mostrando a imagem difusa, devido aos bifilmes dobrados; b) 0,01 atmosfera, com os bifilmes abertos (2).

Figura 12 - Representação dos tipos de filtros cerâmicos utilizados na fundição de alumínio pelo processo de areia a verde :a) tipo "crivo"; b) tipo espuma; c) extrudado. (10).

Figura 13 - Formatos e porosidades de alguns filtros cerâmicos tipo espuma utilizados na fundição das ligas de alumínio em areia de moldagem (15)

Figura 14 - Mecanismos de aderências das partículas durante a passagem do metal líquido através dos filtros cerâmicos (16).....

Figura 15 - Quatro projetos de sistemas de canais: sem filtro (UFUT); sem filtro e com o canal de distribuição afilado (UFT) - as secções maiores estão próximas ao canal de ataque, (para diminuir a velocidade do fluxo); com filtro na posição horizontal ( HF); com filtro na posição vertical (VF) (14).

Figura 16 - Defeitos encontrados abaixo da superfície dos corpos de prova, correspondentes a cada um dos quatro sistemas de enchimento. A altura do canal de descida foi de $585 \mathrm{~mm}$ (da superfície externa da caixa de moldar superior, até a bacia do canal de descida), conforme os projetos UFUT, UFT, VF e HF. A fotografia mostra que houve turbulência nos canais sem filtros. (14).

Figura 17 - Gráfico relacionando a velocidade teórica do metal com a velocidade medida no canal de distribuição. (14). 37

Figuras 18 Figura 18 - Micrografias apresentando o aspecto dos filmes de óxidos nas secções dos corpos de prova produzidos conforme o sistema UFUT (a) e UFT (b) (14). 38

Figura 19 - Filme de óxido com o aspecto associado à porosidade na secção do corpo de prova produzido com filtro no sistema de enchimento. (14).

Figura 20 - Imagem do filme de óxido e do poro com o formato dendrítico observados através do M.E.V..O corpo de prova foi obtido com a utilização do filtro no canal de distribuição (14). 
Figura 21 - Esquema da influência do filtro tipo espuma proporcionando a redução da velocidade, da turbulência do fluxo e a retenção de parte das inclusões. (11).

Figura 22 - Corte transversal no canal de distribuição na região do filtro cerâmico tipo espuma, mostrando a grande quantidade de inclusões retidas (18).....41

Figura 23 - Esquemas dos sistemas de canais utilizando os filtros cerâmicos tipo espuma na fundição das peças em liga de alumínio. (16)

Figura 24 - Efeito da velocidade de crescimento das bolhas, a forma, o tamanho e o envolvimento pelo líquido. (9)

Figura 25 - Gráfico relacionando o espaço entre os braços das dendritas com as propriedades mecânicas (2).

Figura 26 - Relação entre o tempo de solidificação, tamanho das microporosidades e o tempo previsto para ocorrer a ruptura por fadiga (8). 45

Figura 27 - Radiografia de barras fundidas em areia de moldagem, com e sem o tratamento de modificação com sódio. A porosidade aparece em escuro. Os níveis de sódio de cima para baixo foram zero, 0,002\%, 0,003\%, traços, 0,012\%. (5). .46

Figura 28 - Radiografia de barras fundidas em areia de moldagem, com e sem o tratamento de modificação com estrôncio A porosidade aparece em escuro. Os níveis de sódio de cima para baixo foram zero, zero, 0,003\%, 0,009\%, 0,012\% e 0,0018\%. (5) 47

Figura 29 - Esquema da influência da pressão e do teor de gás na formação dos poros na zona de solidificação pastosa de uma liga de alumínio ( 8).49

Figura 30 - Geometria da bolha em contato com o sólido, apresentando: a) pouco molhamento e relativamente baixa coesão entre o líquido e o sólido; b) molhamento médio; c) bom molhamento, com elevada coesão entre o líquido e o sólido - a bolha vai ser deslocada para o núcleo do líquido, fora do contato com o sólido, onde a energia é mais favorável (10)....50

Figura 31- Relação entre o teor de hidrogênio, o espaço entre os braços das dendritas e a quantidade de poros por $\mathrm{cm}^{2}(8)$. .51

Figura 32 - Correlação entre o teor de silício e a quantidade dos defeitos de contração numa liga $\mathrm{Al}-\mathrm{Si}$; à esquerda desgaseificada e à direita com enriquecimento de gás. $V_{\text {rech }}$ é o volume dos rechupes; $V_{\text {depres }}$ é o volume 
superficiais em depressão; $V_{\text {microporos é o volume das microporosidades }}$ (8).

Figura 33 - Correlação entre a microporosidade e o teor de hidrogênio nas ligas Al 10Si e Al 7Si (8). .53

Figura 34 - Efeito da temperatura de têmpera na densidade das ligas Al4Si. (8).....54

Figura 35 - Esquema representando a localização das porosidades de contração ou rechupes (8).

Figura 36 - Metalografia do corpo de prova, resfriado rapidamente a $590^{\circ} \mathrm{C}$, apresentando dendritas de fase a e eutético extremamente refinado, correspondendo à fase líquida no momento da solidificação. Sem ataque, $125 \times(4)$.

Figura 37 - Representação esquemática dos cinco mecanismos de alimentação na solidificação de um produto fundido, relacionados por Campbell (10)...58

Figura 38 - Esquema de uma superfície turbulenta, agindo para dobrar o filme de óxido e envolver as bolhas. (2)

Figura 39 - Superfície da fratura da liga de alumínio, correspondente à parte central da micrografia, onde são observados filmes de óxidos dobrados, com espessura de $20 \mathrm{~nm}$.

Figuras 40 e 41 - Verificação da superfície da fratura na peça com a liga Al 11Si 0.6Fe através do M.E.V..Observa-se o aspecto do filme dobrado que proporcionou a fratura, com as metades opostas na superfície da falha (2). 62

Figura 42- Representação do envolvimento das inclusões e da imersão das interfaces não unidas (2).

Figura 43 - Imagem da fratura na superfície do produto fundido com $\mathrm{Al} 4.5 \mathrm{Cu}$ observada através do M.E.V. A análise da micrografia acima e à esquerda mostra que houve turbulência e a conseqüente entrada do bifilme no interior do produto, que está estirado devido ao crescimento das dendritas. O filme de óxidos, quase invisível, cobre toda a superfície e pode ser observado à direita (acima), com o aspecto dobrado, indicado pela seta. Abaixo e à esquerda, foi analisada outra parte do produto após vazamento sem turbulência. Na fratura aparece a influência dos primeiros bifilmes. Na micrografia à direita e na parte inferior, pode-se 
observar o resultado da fratura dúctil, confirmando o contato metal / metal (2).

Figura 44 - Separação das superfícies dos óxidos e o aumento do volume do poro: a) comportamento do bifilme dobrado; b) bifilmes emaranhados; c) grande aumento do volume com o formato final esférico; d) crescimento dos bifilmes nos últimos estágios de solidificação, resultando em poros interdendriticos. (2) .64

Figura 45 - (a) vista em planta, 45 (b) vista em corte e 45 (c) perspectiva - Desenho da "Tampa do cilindro RCF".

Figuras 46 - (a) e (b)- peça em bruto com as faces correspondendo respectivamente ao molde inferior e ao superior 71

Figuras 47 - ( a) e (b) - Vistas do conjunto peça em bruto, sistema de enchimento e os massalotes laterais. 72

Figura 48 - (a) corresponde à placa modelo superior e a 48 (b) à placa modelo inferior .73

Figura 49 - Localização do filtro cerâmico tipo espuma no canal de descida. O filtro com 10 ppp* (dimensões:diâmetro $40 \mathrm{~mm}$ e espessura 12,5 mm) fica localizado a cerca de $70 \mathrm{~mm}$ acima do molde inferior. Representações :1- canal de descida; 2 e 3 - alimentadores; 4 - canal de distribuição. .74

Figuras 50 (a), (b), (c) e (d) - Dimensões das seções principais dos canais de descida, distribuição e dos massalotes (alimentadores).....................75

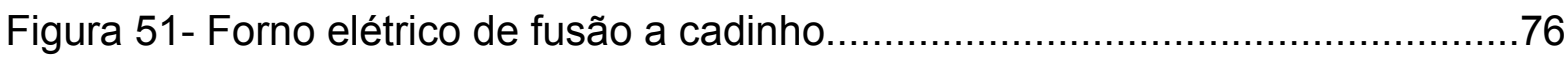

Figura 52 - Pirômetro de imersão utilizado para verificar as temperaturas do

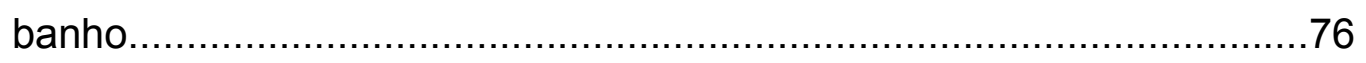

Figura 53 - Escumadeira, conchas e sino sendo aquecidas pelo calor do forno.... 76

Figura 54 - Conjunto de caixas de moldagem superior e inferior. 78

Figura 55 - Moldes na área de vazamento sobre a esteira de roletes. .80

Figuras 56 (a) e (b) - llustrações do processo de vazamento dos moldes.

Figura 57 - Conjunto do sistema de canais de vazamento com filtros 10 ppp e massalotes laterais

Figuras 58 (a) e (b) - Em (a) observa-se a preparação da peça para o teste de estanqueidade no conjunto montado, onde são colocados anéis vedantes de borracha, eixo de aço e bucha de polímero; em (b) 
encontra-se o conjunto montado, sendo submetido à pressão de 8 bar e a tampa coberta por camada de óleo.

Figura 59 - Recobrimento da superfície com o líquido penetrante ........................84

Figura 60 - Módulos de resfriamentos das partes componentes da peça................86

Figuras 61 a) e b) - Fotos do sistema de desgaseificação com rotor durante o processo.

Figura 62 - Placa - modelo superior, onde aparecem o modelo invertido em relação ao plano de partição e o novo sistema de canais de vazamento.

Figura 63 - Dimensões do novo sistema de canais (o diâmetro do canal de descida é $40 \mathrm{~mm})$.

Figura 64 (a) - Resfriador em ferro fundido: base maior 40 e menor 34, altura 30 e comprimento180 $\mathrm{mm}$. .90

Figura 64 (b) - Detalhes da superfície do resfriador em contato com o metal líquido

Figura 65 - Luva exotérmica: diâmetros inferiores - interno 22 mm e externo 42 mm; diâmetros superiores - interno $45 \mathrm{~mm}$ e externo $65 \mathrm{~mm}$. .90

Figura 66 - Dimensões dos filtros: $37 \times 37 \times 12,5$; a foto da esquerda corresponde a 10 ppp (poros por 25,4 mm de comprimento linear e o da direita a 20 ppp.

Figura 67 - Placa modelo inferior, conjunto de caixas de moldagem para o processo squeezer e os dois resfriadores

Figura 68 - Placa modelo superior com o conjunto de luvas exotérmicas e os resfriadores

Figura 69 - Molde inferior com os resfriadores apresentando ranhuras superficiais.93

Figura 70 - Molde superior com os resfriadores, o filtro cerâmico no sistema de canais e as luvas exotérmicas. .94

Figuras 71 (a) e (b) - Ilustrações do processo de vazamento. .94

Figura 72 - Conjunto do sistema de canais de vazamento com filtros 10 ppp, massalotes obtidos através das luvas exotérmicas e resfriadores metálicos em ambos os moldes.

Figura 73 - Conjunto peça em bruto com o sistema de canais, massalotes e resfriadores só no molde inferior. .95

Figura 74 - Foto do rotor de grafite apresentando desgaste excessivo. .96 
Figura 75 - Rotor novo que foi utilizado na segunda experiência. Nesta posição é possível observar um dos quatro furos por onde o nitrogênio deve passar.

Figura 76 - O rotor é fixado na haste através do niple (componentes de grafite)....97

Figuras 77 (a) e b) - Aquecimento do conjunto rotor de grafite, haste e placa defletora.

Figura 78 - Dimensões da luva exotérmica utilizada na $2^{\mathrm{a}}$ experiência: diâmetro interno $45 \mathrm{~mm}$, externo de $65 \mathrm{~mm}$ e altura $150 \mathrm{~mm}$

Figura 79 - Posicionamento dos resfriadores e das luvas exotérmicas no modelo superior

Figura 80 - Execução dos quatro furos para auxiliar na extração de gás 100

Figuras 81 (a) e (b) - Aspecto irregular nas superfícies da peça devido ao uso dos resfriadores e os massalotes (com maiores dimensões, gerados através das novas luvas exotérmicas).

Figuras 82 - Resultado da inspeção por fluoroscopia, onde se pode notar altos índices de porosidade; na região que fica na ponta do clipe ocorreu o vazamento no teste de estanqueidade. 102

Figura 83 - Resultado do ensaio por líquido penetrante na peça confeccionada pelo processo normal de produção e que foi reprovada no teste de estanqueidade. 103

Figura 84 (a) A região do vazamento fica localizada no centro da peça, onde é observado um rebaixo produzido pela usinagem. 103

Figuras 84 (b) - Detalhes com ampliação da região que apresentou vazamento no teste de estanqueidade. 104

Figura 85 - Corte da peça e a retirada das amostras na região que apresentou o vazamento no teste de estanqueidade (região central) e na lateral superior, correspondendo à região de alimentação pelo massalote...104

Figura 86 - Amostra preparada (embutida, lixada e polida), retirada da região lateral conforme pode ser observado na Figura 85. Observa-se grande quantidade de microporosidades. Sem ampliação. 105

Figura 87 - Amostra preparada, retirada da região central que apresentou vazamento no teste de estanqueidade. Há elevado nível de porosidades concentradas, com probabilidade de interconexão. Sem ampliação....105 
Figura 88 - Comparação entre as amostras retiradas da região central e da lateral. Embora ambas apresentem muita porosidade observa-se maior quantidade e com provável interconexão na amostra central (à esquerda). Sem ampliação.

Figura 89 - Observação em lupa estereoscópica das porosidades na amostra correspondente à região central. 10x .106

Figura 90 - Observação em lupa estereoscópica da amostra correspondente à região lateral. $10 \mathrm{x}$ 107

Figura 91 - Dendritas fase $\alpha$, eutético modificado $\alpha+\operatorname{Si}$ e a presença de porosidades de rechupe (grande tamanho e com sinais de interconexão). Microscópio óptico com aumento de $25 x$ 107

Figura 92 - Dendritas fase $\alpha$, eutético modificado $\alpha+\operatorname{Si}$ e a presença de porosidades de rechupe (grande tamanho e com sinais de interconexão). Microscópio óptico com aumento de $25 x$. 108

Figura 93 - Dendritas fase $\alpha$, eutético modificado $\alpha+S i$ e a presença de porosidades de rechupe (grande tamanho e com sinais de interconexão). Microscópio óptico com aumento de $25 x$ 108

Figura 94 - Dendritas fase $\alpha$, eutético modificado $\alpha+S i$ e a presença de porosidades de rechupe (grande tamanho e com sinais de interconexão). Microscópio óptico com aumento de 100x 109

Figura 95 - Dendritas fase $\alpha$, eutético modificado $\alpha+\operatorname{Si}$ e a presença de porosidades de rechupe (grande tamanho e com sinais de interconexão). Microscópio óptico com aumento de $100 x$ 109

Figura 96 - Dendritas fase $\alpha$, eutético modificado $\alpha+$ Si e a presença de porosidades de rechupe (grande tamanho e com sinais de interconexão). Microscópio óptico com aumento de $100 x$

Figura 97 - Estrutura apresentando fase a e eutético a + Si modificado pela presença do sódio. Microscópio óptico, aumento de $100 x$

Figura 98 - Estrutura apresentando fase $\alpha$ e eutético $\alpha+$ Si modificado e a presença de microporosidades. Microscópio óptico com aumento de 25x 
Figura 99 - Estrutura apresentando fase a e eutético $\alpha+$ Si modificado e a presença de microporosidades. Microscópio óptico com aumento de 25x

Figura 100 - Estrutura apresentando fase a e eutético $\alpha+S i$ modificado e a presença de microporosidades. Microscópio óptico com aumento de $25 x$

Figura 101 - Estrutura apresentando fase a e eutético $\alpha+$ Si modificado e a presença de microporosidades. Microscópio óptico com aumento de $25 x$.

Figura 102 - Estrutura apresentando fase a e eutético $\alpha+$ Si modificado e a presença de microporosidades. Microscópio óptico com aumento de $100 x$.

Figura 103 (a) - Observação da amostra retirada da região crítica; em (1) observamse as dendritas fase $\alpha$, em contato com as porosidades de rechupe; na região (2) ocorre a presença do eutético Al-Si. Microscópio eletrônico de varredura com aumento de 100x

Figura 103 (b) e (c) - Resultados da análise obtidas por EDS nas regiões (1) e (2) selecionadas através do M.E.V..... 114

Figura 104 - Micrografia na região próxima à fratura onde ocorreram as porosidades de rechupe.Observa-se a presença das dendritas fase $\alpha$, eutético $\alpha+\mathrm{Si}$ modificado e a presença do eutético $\mathrm{Al}-\mathrm{Mg}_{2} \mathrm{Si}$. Microscópio eletrônico de varredura com aumento de $200 x$ 115

Figura 105 - Detalhe ampliado da Figura 74, onde ocorre a presença das dendritas fase $\alpha$, eutético $\alpha+$ Si modificado e a presença do eutético $\mathrm{Al}-\mathrm{Mg}_{2} \mathrm{Si}$. Microscópio eletrônico de varredura com aumento de 1000x. 115

Figura 106 - Módulos de resfriamentos das partes componentes do produto. 117

Figura 107 - Peça fundida utilizando-se filtro 10ppi, resfriadores em ambos os moldes e luvas exotérmicas. 118

Figura 108 - Detalhe da região central com porosidade somente entre os resfriadores., nas proximidades das regiões dos massalotes 118

Figura 109 - Peça fundida utilizando filtro com 20 ppi luvas exotérmicas e resfriadores só no molde inferior. 118

Figura 110 - Detalhe da região central. 118

Figura 111 - Observa-se a comparação entre o resultado da inspeção por líquido penetrante na peça produzida pelo processo de produção (na parte 
central e em cima, com furos obtidos por usinagem) e as demais obtidas após o primeiro ajuste no processo de fabricação.

Figura 112 - Detalhe da disposição apresentada na Figura 110, podendo-se observar os melhores resultados nas peças após ajuste do processo de fabricação (peça à direita).

Figura 113 - Exame por fluoroscopia, onde não foram observadas ocorrências de porosidades.

Figura 114 - Cortes efetuados na peça com resfriadores no molde inferior e luvas exotérmicas (com as dimensões indicadas na figura 84), para verificar a ocorrência das porosidades.

Figura 115 - Amostra retirada da região central da peça (correspondendo à área de maior concentração de porosidades) fundida com resfriadores no molde inferior, 10x.

Figura 116 - Amostra retirada da região central da peça fundida com resfriadores no molde inferior. Lupa estereoscópica com aumento de 10x.

Figura 117 - Microestrutura constituída por dendritas de fase $\alpha$, eutético $\alpha+\mathrm{Si}$ modificado, eutéticos $\mathrm{Al}-\mathrm{Mg}_{2} \mathrm{Si}$ e $\mathrm{Al}-\mathrm{Al} \mathrm{I}_{15}(\mathrm{Fe}, \mathrm{Mn})_{3} \mathrm{Si}_{2}$ e microporsidades. Microscópio óptico com aumento de 25x.

Figura 118 - Microestrutura constituída por dendritas de fase $\alpha$, eutético $\alpha+\mathrm{Si}$ modificado, eutéticos $\mathrm{Al}-\mathrm{Mg}_{2} \mathrm{Si}$ e $\mathrm{Al}-\mathrm{Al}{ }_{15}(\mathrm{Fe}, \mathrm{Mn})_{3} \mathrm{Si}_{2}$ e microporsidades. Microscópio óptico com aumento de 25x 122

Figura 119 - Microestrutura constituída por dendritas de fase $\alpha$, eutético $\alpha+\mathrm{Si}$ modificado, eutéticos $\mathrm{Al}-\mathrm{Mg}_{2} \mathrm{Si}$ e $\mathrm{Al}-\mathrm{Al}{ }_{15}(\mathrm{Fe}, \mathrm{Mn})_{3} \mathrm{Si}_{2}$ e microporsidades. Microscópio óptico com aumento de 25x. 123

Figura 120 - Microestrutura constituída por dendritas de fase $\alpha$, eutético $\alpha+\mathrm{Si}$ modificado, eutético $\mathrm{Al}-\mathrm{Mg}_{2} \mathrm{Si}$ e $\mathrm{Al}-\mathrm{Al}{ }_{15}(\mathrm{Fe}, \mathrm{Mn})_{3} \mathrm{Si}_{2}$ e microporsidade. Microscópio óptico com aumento de 100x 123

Figura 121 - Microestrutura constituída por dendritas de fase $\alpha$, eutético $\alpha+\mathrm{Si}$ modificado, eutéticos secundários $\mathrm{Al}-\mathrm{Mg}_{2} \mathrm{Si}$ e $\mathrm{Al}^{-\mathrm{Al}}{ }_{15}(\mathrm{Fe}, \mathrm{Mn})_{3} \mathrm{Si}_{2}$ e microporsidade. Microscópio óptico com aumento de 100x.

Figura 122 - Microestrutura constituída por dendritas de fase $\alpha$, eutético $\alpha+\mathrm{Si}$ modificado e eutéticos secundários ( $\mathrm{Al}-\mathrm{Mg}_{2} \mathrm{Si}$ e $\left.\mathrm{Al}-\mathrm{Al}{ }_{5} \mathrm{FeSi}\right)$. Microscópio óptico com aumento de 100x. 124

Figura 123 - Módulos de resfriamento das regiões A e B e dos massalotes. 125 
Figura 124 - Peça submetida ao ensaio por líquido penetrante. 126

Figura 125 (a), (b) e (c) - Fotos do processo de usinagem das peças da experiência. 126

Figuras 126 (a),(b), (c) e (d) - Resultado da inspeção por fluoroscopia, onde não foram observadas microporosidades ou porosidades de rechupe.......128

Figura 127 - Seções para a preparação das amostras 129

Figura 128 - Amostra preparada (embutida, lixada e polida), retirada da região crítica. Observa-se menor quantidade de microporosidades e de pequenas dimensões e mais distribuídos do que no experimento anterior. Sem ampliação.

Figura 129 - Microporosidades distribuídas, observadas em lupa estereoscópica. Aumento de 10x. 130

Figura 130 - Microestrutura constituída por dendritas de fase $\alpha$, eutético $\alpha+\mathrm{Si}$ modificado, inclusões ricas em Ti e microporosidade. Microscópio óptico com aumento de $25 x$. .130

Figura 131 - Microestrutura constituída por dendritas de fase $\alpha$, eutético $\alpha+\mathrm{Si}$ modificado, inclusões ricas em Ti e microporosidade. Microscópio óptico com aumento de25x

Figura 132 - Microestrutura constituída por dendritas de fase $\alpha$, eutético $\alpha+\mathrm{Si}$ modificado, inclusões ricas em Ti e microporosidade. Microscópio óptico com aumento de $25 x$. .131

Figura 133 - Microestrutura constituída por dendritas de fase $\alpha$, eutético $\alpha+\mathrm{Si}$ modificado, inclusões ricas em Ti e microporosidade. Microscópio óptico com aumento de $100 x$.

Figura 134 - Microestrutura constituída por dendritas de fase $\alpha$, eutético $\alpha+\mathrm{Si}$ modificado, inclusões ricas em Ti e microporosidade. Microscópio óptico com aumento de $100 x$ 132

Figura 135 - Microestrutura constituída por dendritas de fase $\alpha$, eutético $\alpha+\mathrm{Si}$ modificado, inclusões ricas em Ti e microporosidade. Microscópio óptico com aumento de 100x.

Figura 136 - Microestrutura constituída por dendritas de fase $\alpha$, eutético $\alpha+S i$ modificado, inclusões ricas em Ti e microporosidade. Microscópio óptico com aumento de 100x. 
Figura 137 - Microestrutura constituída por dendritas de fase $\alpha$, eutético $\alpha+\mathrm{Si}$ modificado, inclusões ricas em Ti e eutéticos secundários $\mathrm{Al}-\mathrm{Al}-\mathrm{Mg}_{2} \mathrm{Si}$ e $\mathrm{Al}-\mathrm{Al}_{15}(\mathrm{Fe}, \mathrm{Mn})_{3} \mathrm{Si}_{2}$. Microscópio óptico com aumento de 100x.......134

Figura 138 - Microestrutura constituída por dendritas de fase $\alpha$, eutético $\alpha+\mathrm{Si}$ modificado, inclusões ricas em Ti e eutéticos secundários $\mathrm{Al}-\mathrm{Al}-\mathrm{Mg}_{2} \mathrm{Si}$ e $\mathrm{Al}-\mathrm{Al}{ }_{15}(\mathrm{Fe}, \mathrm{Mn})_{3} \mathrm{Si}_{2}$. Microscópio óptico com aumento de 100x........134

Figura 139 - Microestrutura constituída por dendritas de fase $\alpha$, eutético $\alpha+\mathrm{Si}$ modificado, inclusões ricas em Ti e eutéticos secundários $\mathrm{Al}-\mathrm{Al}-\mathrm{Mg}_{2} \mathrm{Si}$ e $\mathrm{Al}-\mathrm{Al}_{15}(\mathrm{Fe}, \mathrm{Mn})_{3} \mathrm{Si}_{2}$. Microscópio óptico com aumento de 100x. 135

Figura 140 (a) - Em (1) observa-se precipitação de Ti sobre a matriz com dendritas fase a. Microscópio eletrônico de varredura com aumento de 1000x.

Figura 140 (b) - Resultado da análise obtida por EDS na região (1), selecionadas através do M.E.V. 136

Figura 141- Podem-se observar os índices dos módulos de resfriamento e com a aplicação dos massalotes em ambos os moldes, proporcionando a obediência ao princípio da solidificação direcional 


\section{SUMÁRIO}

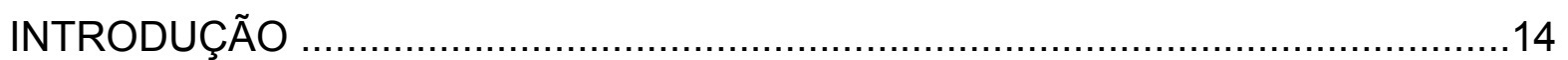

1. REVISÃO DA LITERATURA

$1.1 \quad$ Preparação das ligas Alumínio-Silício.................................................16

1.2 Solidificação das ligas alumínio-silício A356......................................19

1.2.1 Composição química, conforme a especificação da Aluminum

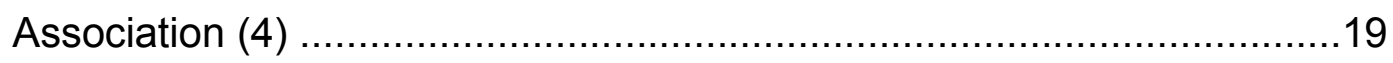

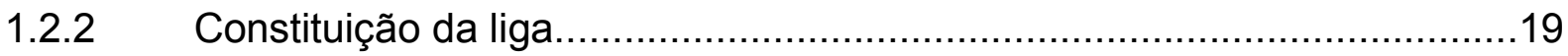

1.2.3 Seqüência na solidificação das ligas A356 ..........................................19

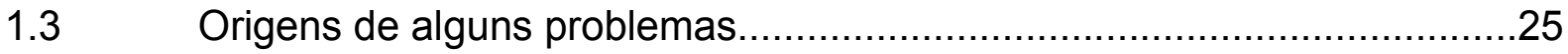

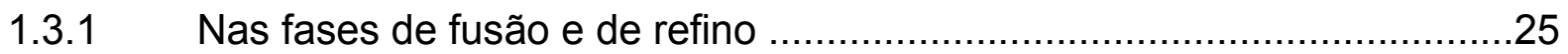

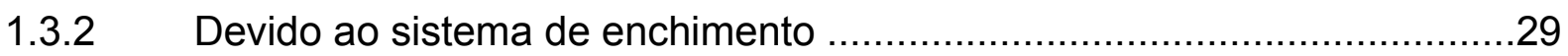

1.3.2.1 Sistemas de enchimento para as ligas de alumínio..................................31

1.3.2.2 Utilização dos filtros cerâmicos para o controle do fluxo...........................33

1.3.3 Defeitos relacionados com a solidificação............................................42

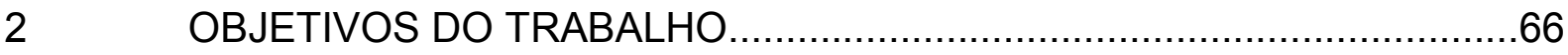

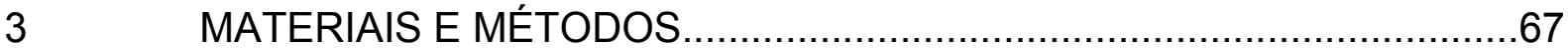

3.1 Seleção da peça de produção para o estudo e a descrição do processo

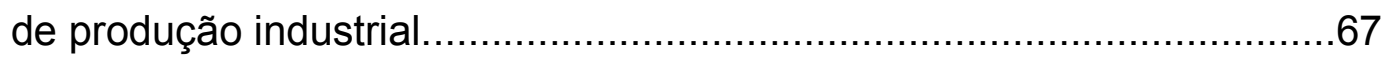

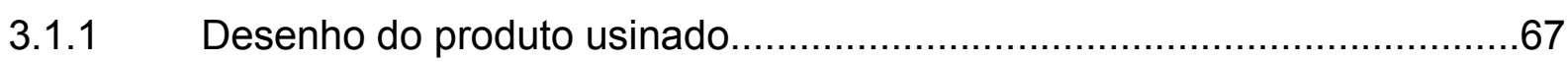

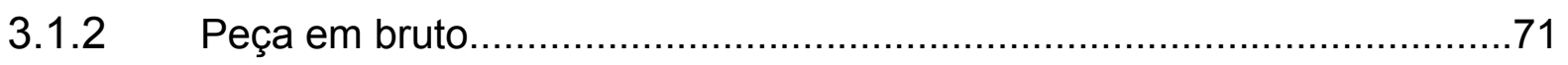

3.1.3 Peça com sistemas de vazamento e alimentação, conforme o processo de

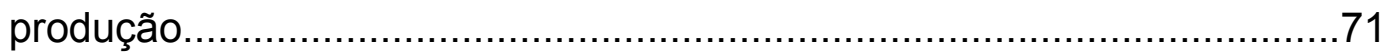

3.1.4 Disposição dos modelos na placa .................................................

3.1.5 Representações e dimensões do sistema de enchimento e de

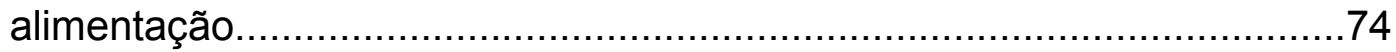

3.1.5.1 Detalhes do sistema de enchimento e alimentação.................................74

3.1.6 Processo de preparação do metal.............................................76

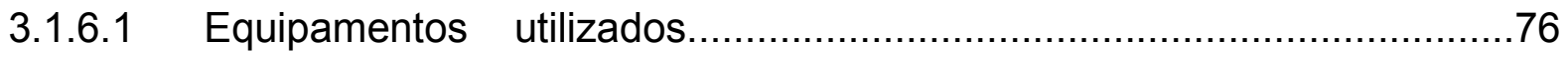

3.1.6.2 Materiais constituintes da carga, fluxo para limpeza do banho e o elemento modificador do eutético.........................................................

3.1.6.3 Metodologia para elaborar o metal................................................... 
3.1.7 Preparação da areia de moldagem - areia à verde..................................77

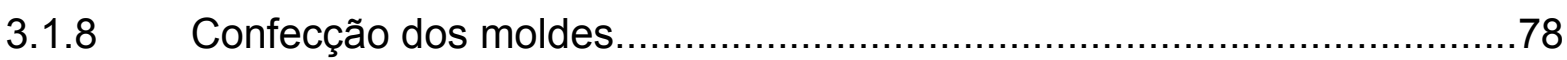

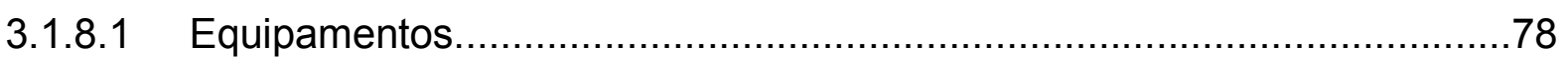

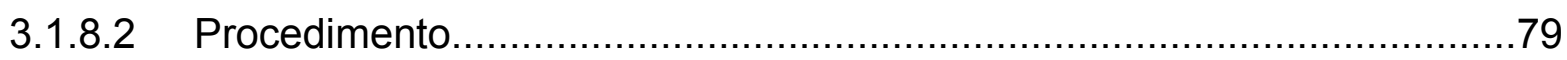

3.1.8.2.1 Confecção do molde inferior...........................................................

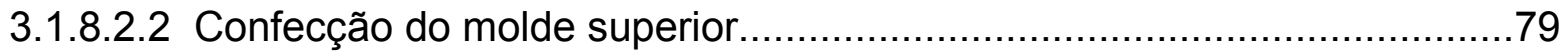

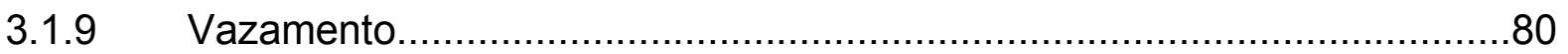

3.1.10 Corte, acabamento, limpeza e usinagem ….................................... 82

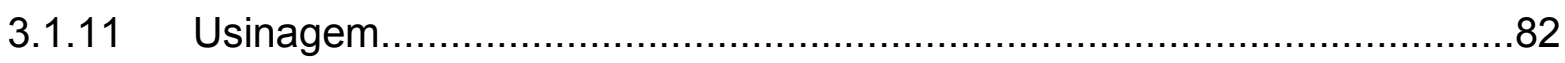

3.2 Caracterização das peças de produção.................................................82

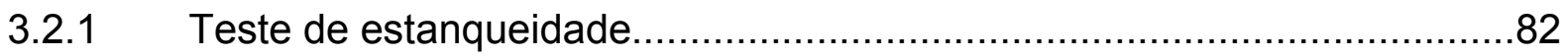

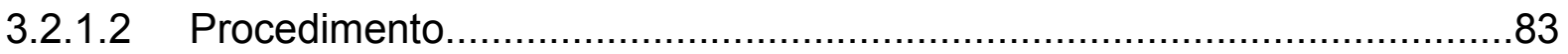

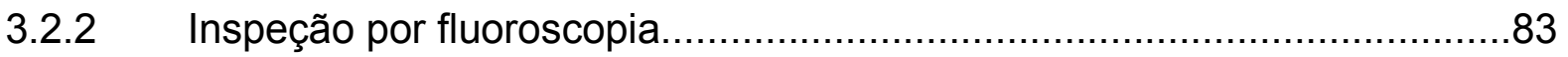

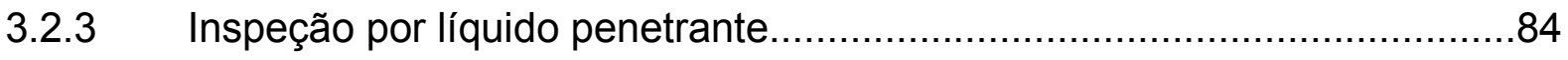

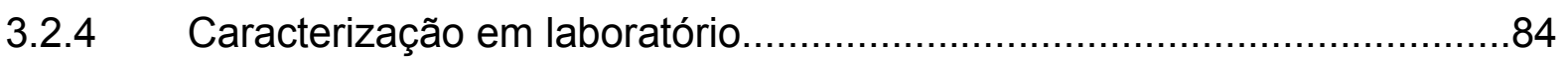

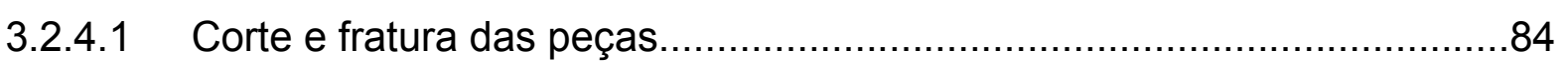

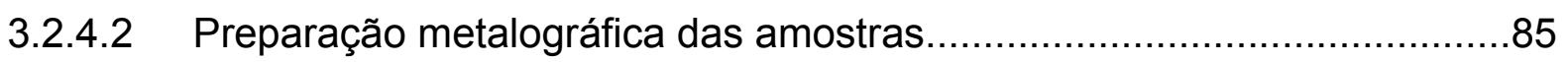

3.2.4.3 Observação em lupa estereoscópica, em microscópio óptico, microscópio eletrônico de varredura e microscópio de emissão de

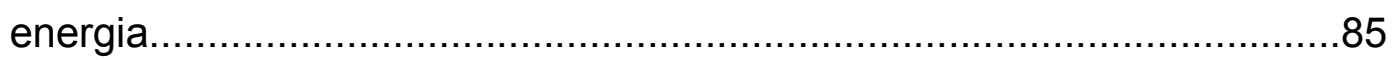

3.3. Módulos de resfriamento do produto e do sistema de alimentação..........85

3.4 Primeira série de ajustes do processo de produção da peça......................86

3.4.1 Preparação do metal líquido - fusão e refino...........................................86

3.4.1.1 Materiais constituintes da carga, fluxo para limpeza do banho, ante-liga para o refino do grão e elemento modificador do eutético..........................87

3.4.1.2 Metodologia para a elaboração do metal.............................................87

3.4.2 Preparação da areia de moldagem - areia à verde.................................8

3.4.3 Preparação das placas com os modelos (superior e inferior) ……….......88

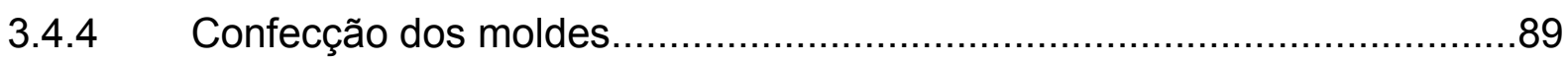

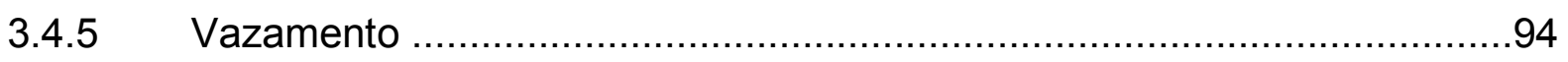

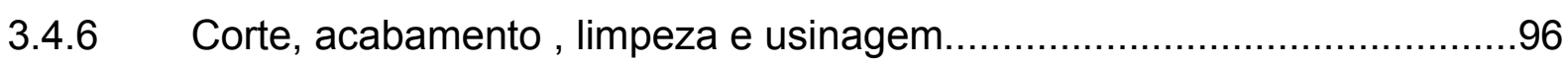

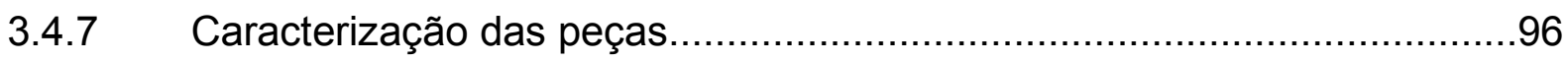

3.5 Segunda série de ajustes no processo de produção................................96

3.5.1 Preparação do metal líquido - fusão e refino...........................................96 


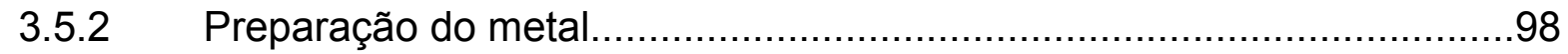

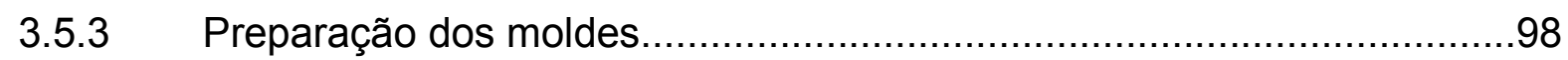

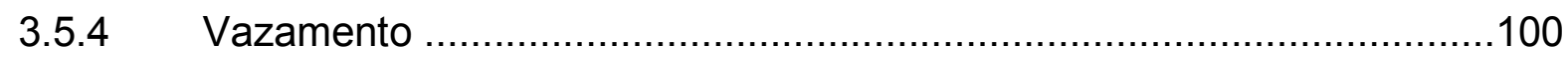

3.5.5 Rebarbação, acabamento, limpeza, e usinagem................................101

3.5.6 Caracterização das peças...............................................................101

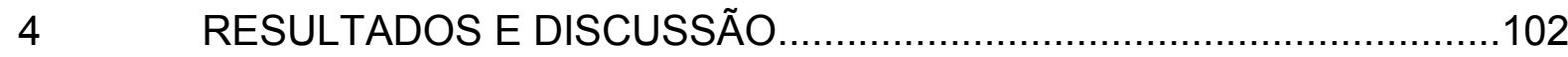

4.1 Resultados de caracterização das peças da série de produção .............102

4.2 Análise do sistema de alimentação da peça de produção......................116

4.3 Alterações necessárias para corrigir as microporosidades.................. 117

4.3.1 Resultados da primeira série de alterações no processo de produção.118

4.3.2 Resultados da segunda série de alterações no processo de produção.126

4.4 Rendimentos metálicos alcançados nas três séries de produção..........137

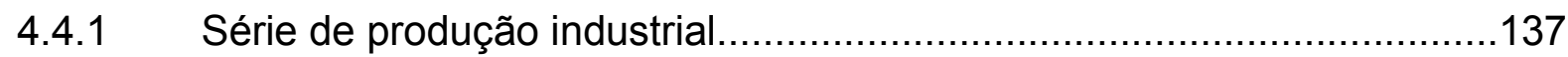

4.4.2 Primeira série de alterações no processo de produção..........................138

4.4.3 Segunda série de alterações no processo de produção..........................138

4.4.4 Análise geral dos resultados das duas séries de experimentos..............138

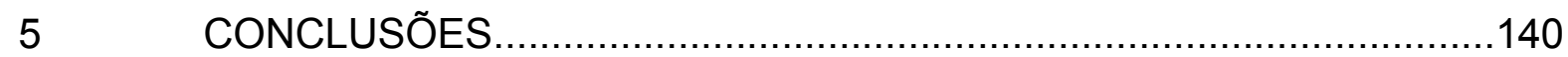

$6 \quad$ SUGESTÕES PARA OS TRABALHOS FUTUROS..............................141

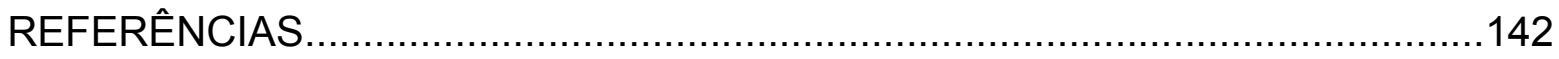

APÊNDICE I - RESULTADOS DE COMPOSIÇÃO QUÍMICA................................144 